\title{
Growth in the Application of Telemedicine and E-Health
}

\section{Charles R. Doarn*}

The integration of communications, information technology (IT) and sensors has provided a strong foundation for changes in how medical care can be practiced and how populations across the globe access health information. Over the past century or so, we have seen the world change as a result of innovation in telecommunications, computers, television, antibiotics and the list goes on. These innovations have changed the facts like how we live, how we acquire information, how we interact with each other, how we conduct business, and yes, how we see our physician. Introduction and rapid acceleration and utilization of the Internet and cell phones have changed nearly every aspect of human life. These engineering marvels provide much more significant tools for addressing health issues worldwide than at any time in human history.

At the dawn of the space age, technology provided a unique opportunity for people on the ground to monitor the health of individuals in space and on the surface of the moon. These technologies found their way into research initiatives through the ensuing 20 years or so; and it was not until the concept of integrating telecommunications and medicine together to support medical response to a disaster (a massive earthquake) in the Spacebridge to Armenia that the term telemedicine became a new word that was increasingly being used. While there are examples worldwide--the space program, flying doctors in Australia, utilization of the radio for health between various countries and Antarctica-the concept really didn't take off in a sustainable way until the 1990s.

The ushering in of the rapidly growing Internet, the development of the World Wide Web, and of course the cell phone or now the smart phone has created a plethora of opportunities in health monitoring, awareness, and education. Often called a perfect storm, these tools permit a much wider access to knowledge, data, remote monitoring, and even surgical care. Once bandwidth and cellular technology became much less expensive in the first decade of the $21^{\text {st }}$ Century, the second decade saw an exponential growth of applications both in the utility of telemedicine and e-health but also the growing development of smartphone-based applications. Of course, there has also been development and adoption of electronic health records and robust health IT (HIT) networks and various systems to support the exchange of data at high levels and the subsequent capability to rapidly evaluate, assess, and analyze data in the emerging field of medical and public health informatics.
What started out as a tool for monitoring or assessing the health status of individuals in faraway places like the moon or the remote regions of the earth has now become universally available worldwide. While the penetration of cellular networks and utilization continues to grow there has been a steady stream of peer-reviewed research that has been published in scientific literature. The research has provided a strong foundation for change and has been key to implementing new and innovative approaches and strategies to home-based monitoring, a key component of the patient-centered medical home, global health, and education.

As a professor of family and community medicine at the University of Cincinnati and on assignment to NASA, it was a great opportunity to be involved in telemedicine and e-health on an international scale. As the editor in chief of the Telemedicine and e-Health Journal, it was the opportunity to see firsthand the application of HIT technologies around the world. Over the past two decades, I have been involved in research in telerobotic surgery in unique and extreme environments, the delivery of healthcare in international settings, and increasing awareness and capability of how the tools in telemedicine and e-health can be used in developing world or in the aftermath of a disaster.

The unique opportunity that we have as faculty in academic medicine, as researchers, and as editors, is that we provide the foundation for change. Our work can help change policy. It can provide new approaches for care and for educational initiatives. The fabric of medicine going forward will be stepped in informatics where large data sets will help us predict new methodologies for being responsive where there may be a shortage of human resources to address unmet needs.

Bioengineering and biomedical science are key disciplines as the $21^{\text {st }}$ century unfolds. The research and the global demand for change so that we can address the determinants of health and achieve the World Health Organization's millennium goals which will grace the pages of this journal.

The work started by our colleagues has provided us a foundation for change and the ability to meet the world's growing needs and challenges of a future world that will have more advanced technology each year moving forward. Our work continues and we will learn from others in the pages of this journal as well as others.

*Corresponding author: Charles R. Doarn, Professor, Family and Community Medicine, University of Cincinnati, Cincinnati, Ohio, USA, E-mail: charles.doarn@ uc.edu

Received October 31, 2012; Accepted November 01, 2012; Published November 04, 2012

Citation: Doarn CR (2012) Growth in the Application of Telemedicine and E-Health J Bioengineer \& Biomedical Sci 2:e113. doi:10.4172/2155-9538.1000e113

Copyright: $\odot 2012$ Doarn CR. This is an open-access article distributed under the terms of the Creative Commons Attribution License, which permits unrestricted use, distribution, and reproduction in any medium, provided the original author and source are credited. 